\title{
Learning about the Predictive Power of Young Voter Party Affiliation and Leadership Perceptions in U.S. Presidential Elections
}

\author{
Adrian B. Popa Ph.D \\ Michael Hazels Ph.D. \\ Deryan Barker, JD
}

\begin{abstract}
Opportunities to observe presidential leadership capacities and to be an active citizen in appraising presidential leadership practices have increased the relevance of perceptions of candidates' leadership qualities in presidential and campaign politics. Based on prior evidence, the current study predicted and confirmed that a sample of 1,087 young voter perceptions of presidential candidates' leadership practices predict intent to vote for a particular candidate after accounting for party affiliation. Additionally, party affiliation was reconfirmed as predicting differences in perceived leadership practices. Interestingly, male and female perceptions of presidential leadership practices varied and were contextualized by factors related to identity development. The study concludes with a discussion of implications as they pertain to leadership theory and leadership education.
\end{abstract}

\section{Introduction}

The U.S. presidential race of 2016 may be remembered as yet another historical election contextualized by partisan political views, divisiveness, global uncertainties of global migration and displacement of refugees, realignment of the European Union, security and terrorism, racial tensions, anti-establishment sentiments, and much more. The U.S. presidency is arguably one the most powerful and visible positions in the free world, and has recently experienced a number of historical demographic changes including diversity of race, gender, religious background, and increasingly more global visibility. In a fast paced, hyper connected world, the complexity of foreign policy influenced by wars, globalization, geopolitics, national security, and the expanding global economy have progressively challenged the role, function, and presence of the United States presidency. The advancement of presidential leadership also reflects shifting complexities in private industry and pace of changing systems and structures. Various systems have been investigated through the lens of leadership theory, documenting progressive shifts from transactional to more transformational models in the presidency (Bass, 1985). As the leader of the "free world" with greater visibility and reach to the common voter, the U.S. president is expected to exemplify the unique balance between a relationship and task oriented behavioral style of leadership. Globally, the escalating and ever changing foreign and domestic complexities facing the current U.S. presidency have resulted in increased visibility and public action from the executive branch. The most current presidential image is vastly different when compared to the traditional presidential roles of the past. Furthermore, the advancements in information technology and social media applications have not only transformed presidential communication 
outreach, but have also broadened the role of the modern president in influencing global policy.

Just as the role of the president has changed over the years, so have the perceptions of presidential followers. During the past decade, researchers have expanded understanding regarding voter perceptions of candidates' leadership practices (e.g. Bueker, Harris, \& Byrnes, 2009; O’Hare, Walter, \& Christopher, 2009; Popa, Hazel, Whatley, Andenoro, \& Crandall, 2011). Popa et al. (2011) found that a relationship exists between a leaders' perceived attributes and voting behavior, and that context acts as a modifier of perceived leadership attributes. Their research was premised on the assertion of Kenny and Rice (1998) that presidential greatness was related to certain contextual factors. Furthermore, the importance of followers' perception of leadership is on the rise (Bennett, 1995; Popa et al., 2011). Nevertheless, there is a gap in research outlining the influence of context on leadership perceptions and attendant outcomes (William, Pillai, Deputla, \& Lowe, 2010). William et al. (2010) argued that the role of context is crucial as it influences both follower cognitions and affect, which are formative elements in the development of leadership perceptions (as cited in Day, 2000). According to Kark and Shamir (2002), it is important to study contextual variables because they serve as mechanisms through which to understand how a leader's identity and his or her resulting effectiveness are shaped.

According to Merolla, Ramos, and Zechmeister (2007), perceptions of charisma are multiplied by contextual circumstances. Popa et al. (2011) argued that perceptions and circumstances are also multiplied by voters' interpretations of leader attributes, which appears to have significant effect on candidate preference even after controlling for impact of party identification and self-perceived political efficacy. As a result, it is important to recognize that context within a presidential election is central to understanding voter perceptions, preferences, and voting behavior. The larger context of the 2008 presidential election was shaded by a country in crisis. The context of the 2008 crisis was marked not only by a plunging financial market but also loss of confidence in corporate leaders and financial institutions. (William et al., 2010). The 2012 election was plagued with similar challenges. At that time, voters were dealing with a fragile economy, controversial healthcare reform, and national debt. The 2008 Presidential election provided useful material to study the selection of a leader during a crisis (William et al., 2010), and the salient contexts for the 2012 election issues were largely based on the 2008 crises. Thus, replicating the study of Popa et al. (2011) in the 2012 election provided an opportunity to investigate and reconfirm how perceived leadership capacity in presidential politics may influence voting when controlling for other salient variables, thereby providing an understanding not only of voting behavior, but potentially the magnitude of the predictive power of perceived leadership practices on voting behavior in presidential elections across varying contexts and time.

\section{Theoretical Background}

Role of Leadership. Values, attitudes, emotions, and ethics all play role in how American presidents lead. Leadership practices such as integrity, visionary thinking, and 
modeling the way of success are exemplary skills desired by constituents. The concepts, theories, and styles that make up leadership have significantly evolved over time. In 1978, there was a shift in the leadership paradigm from trait, behavioral, and contingency models, to ordinary transactional leaders and extraordinary transformational leaders (Barnett, McCormick, and Conners, 2001). Leadership theories tend to focus on the leader as a person (Bess and Goldman, 2001). Postmodern leadership approaches continue to provide a framework of study, evidence to expound upon, and practical applications to apply in various circumstances. Yukl (1995) would argue that leadership is more of a social influence process whereby one individual is able to progressively impact others as prerequisite tasks are iteratively accomplished. Gibson, Ivancevich, Donnelly Jr., and Konopaske (2012) share a similar perspective in conceptualizing leadership as a process of influencing others towards achieving a common goal. Furthermore, individuals within a group structure, as well as leaders, share an understanding or expectation of behaviors associated with the role of a leader. When applied to the U.S. government, the president represents executive power and nominal leader. The U.S. constitution provides for a balance of power between three branches of government (executive, judicial, and legislative). It also vests considerable executive power in one person, the president. The president faces many challenges while attempting to lead the nation and its people, including working with the other branches of government while simultaneously attending to issues at home and abroad. According to Cronin and Genovese (1998), the electorate views the president's "vision" as the single most important aspect of presidential leadership.

As the head of government and commander-in-chief of the U.S. armed services, the president is viewed as one of the most powerful people in the world, highly visible to constituents and nominal voters. Given the plethora of roles and responsibilities of a sitting U.S. president, there is a connection between the president's behavior and leadership style. Nevertheless, that investigation has not been thoroughly extended to voting behavior. Some studies have linked perceptions of presidential leadership with voting behavior (Emrich, Holly, Feldman, \& Garland, 2001; Goethals, 2005; Kenney \& Rice, 1988; Merolla et al., 2007; Pillai \& Williams, 1998; Popa et al., 2011; Simonton, 2001), yet the complexity of predictive models are malleable and shaped by context and generational cohorts.

Pillai and Williams (1998) were the first to present the relationship between U.S. voters taking perceptions of leadership ability into consideration when choosing a president. They argued that there existed a link between transformational and charismatic leadership on voting behavior. Popa et al. (2011) extended the Pillai and Williams study, finding a similar relationship. In addition, Popa et al. (2011) "examined how respondents with contrasting party affiliations differed with respect to political efficacy, political ideology, and intent to vote" (Popa et. al., 2011, p. 37). By applying leadership prototyping they found that "party affiliation is a strong determinant in voter choices and biases the voters' assessment or perceptions of the leader's abilities and attributes" (Popa et. al, 2011, p.37). Popa et al. (2011), Foti, Frasier and Lord (1992), and Maurer, Maher, Ashe, Mitchell, Hein, and Hein (1993) all found a link between trait prototyping and leadership ratings of political leaders. Therefore, prototyping research is 
a proven tool used to identify voter perceptions on candidate leadership practices.

This study continues where Popa et al. (2011) study ended. By using prototyping research the current paper explores the relationship of five leadership practice ratings by young voters in the 2012 presidential election. Specifically, the study investigates the correlation between young voter's perceived presidential leadership practices and how those roles, combined with party affiliation and controlling for other salient variables, impact their likely voting behavior.

Transformational Leadership. "Transformational leadership occurs when a leader inspires followers to share a vision, empowering them to achieve the vision, and provides the resource necessary for developing their personal potential" (Antonkais, Avolio, \& Sivasubramaniam, 2003, p. 265). Transformational leaders serve as role models, support optimism, and mobilize commitment, as well as focus on the followers' needs for growth (Bass, 1996; Bass \& Avolio, 1988, 1994a, 1994b). They have a strong set of values, ideals, and are effective in motivating followers to support a greater good over self-interest. In the 2012 presidential election voters were looking to elect a leader who would address issues such as the erratic conditions and uncertainty resulting from the economic recovery of the Great Recession (Hollin and Prysby, 2014). Other issues included legislation such as the Affordable Care Act, national debt, education, taxes, and help with the middle class. According to Hater and Bass (1998), a follower's attitudes and behaviors are impacted by one's personal identification and shared vision with the leader. The latter is extended by Holian and Prysby's argument that "party identification strongly affects how voters perceive the candidates in personal terms, just as party identification affects other attitudes that affect the vote" (Holian \& Prysby, 2014 p. 498). Additionally, Holian and Prysby argued that leadership and empathy were the most important traits that voters sought in the 2012 presidential election (Holian \& Prysby, 2014).

Transformational leadership was once defined by four leadership characteristics: idealized influence, inspirational motivation, intellectual stimulation, and individualized consideration (Bass \& Avolio, 1994). Nevertheless, transformational leadership characteristics have been redefined over the years. For example Kouzes and Posner (1995) emphasized the importance of exemplary leadership for producing the leaderfollower trust that is central for transformational leadership (Abu-Tineh, Khasawneh, Omary, 2009). According to Kouzes and Posner, there are five practices common to personal best leadership experiences, also known as the Five Practices of Exemplary Leadership (Kouzes \& Posner, 2007). The five practices are 1) Model the way, 2) Inspire a Shared Vision, 3) Challenge the Process, 4) Enable Others to Act, and 5) Encourage the Heart (Kouzes \& Posner, 2007). Both presidential candidates, along the 2012 campaign trail and during the debates, exemplified these practices in various ways. As a result, they showcased the candidate's qualifications for being the U.S president.

Transformational leadership practices may be operationalized through different framing mechanisms (Engbers \& Fucilla, 2012). "Common frames such as 'America the leader,' American dream, 'American ideals,' 'American exceptionalism,' and 'land of 
opportunity' motivate followers to action by instilling them with pride of accomplishment" (Engbers \& Fucilla, 2012 p. 1133). These frames are characterized by the candidate's charisma or idealizing influence along the campaign trail. It is a selfpresentation tool that highlights the candidates' political philosophy. The nexus between charismatic leadership and transformational leadership is magnified during times of crises, potentially leading voters to perceive greater charismatic and transformational characteristics in a candidate (Merolla et.al. 2007; Popa, et al., 2011).

In the 2012 presidential election, President Barack Obama was facing a similar economic crisis to the one he faced in 2008. Studies (e.g. D'Elia \& Norpoth, 2014) have shown how an incumbent can win reelection with a bad economy. D'Elia and Norpoth noted that President Obama faced criticism for his health care legislation, and issues of education, taxes, immigration, foreign policy, and same sex marriage, nevertheless, the primary election issue was the recession and whether the crisis would cause voters to gravitate towards the leader who promised to deliver a hopeful future, as occurred in prior elections (Hunt, Boal, \& Dodge, 1999; Pillai Meindl, 1998; Shamir \& Howell, 1999).

The Role of Party Identification and Leadership. An important role of a public leader is to provide their constituency with a shared identity (Hohman, Hog, \& Bligh, 2010) "The key point of leadership theory is that the more strongly one identifies with a group, and the more important a group is to one's identity and sense of self, the more one is influenced by leaders who are perceived to be prototypical of the group (Hohman, Hogg, \& Bligh, 2010 p. 114). The study by Hohman et al., much like earlier works by Popa et al. (2011) and Pillai and Williams (1998), is derived from criteria including party identification, personal interest, leadership, value congruency between the voter and candidates, and how these variables are influenced by multi-faceted contexts. Context helps to define the roles, relationships, and responsibilities of leaders and their followers. According to William et al. (2009), voter evaluations of candidates' leadership ability, character, and identification with voters' values play a significant role in interpreting voter behavior. Continuing where Popa et al. (2011) left off, the current study examines the party identification of young voters in the 2012 presidential election. Research from Popa et al. (2011), Crespi (1998), Pillai and Williams (1998) found that party affiliation is strong influence on voter behavior. In attempt to further explore the role of party affiliation Williams et al. (2009) set out on a more refined investigation discovering further evidence that voters may be partisan when it comes to evaluating their leaders.

Green and Roberts (2012) investigated party identification in the 2008 election and founds that demographic changes that reflect postmodern and post-material value systems had an impact in the 2008 presidential election. Generation $\mathrm{X}$ has been described as including large number of cynical, mobile, and career savvy people (Green, 2007), while Generation Y is described as diverse, technology savvy, and self-confident (Green \& Roberts, 2012). Consequently, Generation X and Y present connection problems to the traditional politicians in the postmodern era (Green \& Roberts, 2012). Given these demographics, one strategy for Presidential candidates are faced with the challenge of not only inspiring ideological supporters but also independent voters that 
may represent younger generations. In both 2008 and 2012 President Obama sought to unite people in a shared identity. He took the opportunity to connect with his generation and younger voters (Green \& Roberts, 2012). Although Republicans and Democrats saw a decline in new voter registration in 2012, young voters more likely to identified as Democrats (44\% in 2012 and 45\% in 2008) than identify with Republican, Independent and other parties (Pew Research, 2012).

"Young voters desire a leader who inspires and possess a clear vision" (Green and Roberts, 2012, p. 16). Research by Pillai and Williams (1998), Crespi (1998), Hogg (2001) and Popa et al. (2011) all support the belief that party identification is linked to perceptions of leadership practices and that party identification significantly influences voting behavior (Popa et. al.). The findings of Popa et al. (2011) indicated that party identification along with other contextual variables could be effectively used in a prototyping schema to define young voters' perceptions of candidates' leadership practices in the 2008 election. In order to explore the consistency of these relationships in the 2012 U.S. presidential election, the authors investigated if (1) young voter perceptions of presidential candidates' leadership practices predict intent to vote for a particular candidate after accounting for party affiliation, and (2) if party affiliation predicts differences in perceived leadership practices of the two candidates. In addition, given the importance of contexts in learning about the charismatic bond between voter and presidential leadership practices (Madsen \& Snow, 1991), the authors also compared original leadership ratings of the incumbent president in 2008 with ratings in the 2012 reelection.

\section{Method}

Sample and Procedures. One thousand and seven students enrolled at a midsized, private university participated. Of the $92.6 \%$ of respondents who identified their year in school and party affiliation, $21.2 \%$ of the students were freshman, $21.4 \%$ were sophomores, $19.4 \%$ were juniors, $28.2 \%$ were seniors, $2.5 \%$ were fifth year or higher, and $57.7 \%$ identified themselves as female. Thirty-nine percent of the respondents were Democrats, $34.7 \%$ were Republicans, $20.7 \%$ were classified as independent, and $5.8 \%$ specified "other."

The survey was administered electronically before the election during the fall of 2012 to the entire university student body. Respondents were informed about the voluntary and confidential nature of the study and the institution's review board approved procedures. Twenty-three and a half percent of 4,278 students responded to the survey, which included a variety of items including perceptions of the state of the country, likelihood of voting, leadership ratings of both Obama and Romney, political party, political ideology, and self-perceived political efficacy.

Measures. Leadership Practices Inventory. Respondent leadership ratings of the candidates were assessed with the Leadership Practices Inventory (LPI) (Kouses \& Posner, 1998). The 30 item, Likert-type, five point scale instrument measures five dimensions of effective leadership and the scale has consistently high reliabilities and 
sound face and predictive validities (Kouzes \& Posner; Popa et al., 2011). Participants were instructed to rate their perceptions of both candidates on each of the dimensions described below:

Challenge. Challenge is marked by innovation behaviors such as seeking ways to make change and being eager to take risks and experiment. Cronbach's alpha reliability coefficients for this LPI subdimension were .83 for Romney and .86 for Obama.

Inspiring. Inspiring is the ability to communicate a vision of the future that is both contagious for those around and hopeful. The reliability values were .79 for Romney and .85 for Obama.

Enabling. Enabling is the energy that comes with mutual trust between leaders and followers. It is the achieved through collaboration and decision making processes. The reliabilities were .83 for Romney and .90 for Obama.

Modeling. Modeling occurs when leaders enact their own values and beliefs as they work toward progress. The methods of work and achievement enacted by leaders are expected in followers. The reliabilities were .80 for Romney and .89 for Obama.

Encouraging. Encouraging involves recognition. It is the pride communicated through celebrating accomplishments and milestones of individuals and teams toward common goals. The reliabilities were .75 for Romney and .78 for Obama.

Self-perceived Political Efficacy. The Political Efficacy scale (Niemi, Craig, \& Mattei, 1991) is a seven item, five point, Likert-type instrument that measures one's own self-perceived competence to understand and participate in the political process as well as perceptions about the responsiveness of governmental institutions and authorities. In the present study the alpha reliability for was (.70), which is consistent with previous work (.72) (e.g. Popa et al., 2011).

Party Affiliation. In accord with previous research (Pillai \& Williams, 1998; Popa et al., 2011) respondents were asked about party affiliation, with responses anchored in a five point, interval-like scale from "Strong Democrat" to "Strong Republican" with "Centrist/moderate; do not lean either way" in the center of the scale and an "other" category also available.. For the regression analyses, party affiliation was converted to a categorical variable (Democratic $=1$, others $=0),($ Republican $=1$, others $=0)$.

Political Ideology. Respondents indicated their political ideology anchored in an interval-like scale ranging from "Generally speaking, how would you describe your political ideology?" Responses ranged on an interval-like five point scale from "liberal" to "conservative" with "moderate" at the center of the scale.

Intent to Vote. Respondents were asked, "How likely is it that you will be voting in the general election for president in November?" Responses were anchored in an interval-like five point scale ranging from "Definitely will be voting" to "Definitely won't 
be voting." For the purpose of logistic regression analysis, intent to vote was converted to a dichotomous variable (Intend to vote $=1$, other $=0$ ).

Candidate Choice. Respondents indicated their candidate preference by responding to the following question: "Who do you intend to vote for in the 2012 Presidential election?" Categorical responses included the Romney and Obama, as well as "other," "not sure," and "will not vote." For the purpose of logistic regression analysis, voter preference was converted to dichotomous variables (Vote for Obama=1, other=0), (Vote for Romney=1, other=0). Gender was also entered as a control variable.

\section{Data Analysis}

Analysis I. Direct logistic regression analysis using SPSS version 18 was employed to analyze dichotomous criterion variables with a combination of categorical and continuous predictor variables (Neter, Kutner, Nachsheim, \& Wasserman, 1996; Pallant, 2007; Pillai \& Williams 1998). As noted in previous work (Popa, et al., 2011), logistic regression uses chi square statistics and maximum likelihood procedures, and consequently is not as sensitive to violations of the assumptions of normality and constant variance required of ordinary least squares procedures with continuous dependent variables. For this study, we were influenced by the protocols of the Pillai and Williams study, which generated a logistic regression predictive model for the 1994 Clinton/Dole election and the procedures used by Popa et al. (2012) when analyzing these variables from the 2008 election. Thus, our model estimates the influences of the above mentioned variables on both intent to vote and reported candidate preference.

Table 1 displays the model predicting voting preference for Romney regressed on gender, Republican Party affiliation, political efficacy, perceptions of direction of the country, and the individual dimensions of the LPI leadership ratings for Mitt Romney. The full model with all entered predictor variables was statistically significant, $X^{2}(9, N=$ $548)=444.03, p<.001$, indicating that the model predicted voting preferences for Romney. The full model explained between 55\% (Cox and Snell R squared) and 79\% (Nagelkerke R squared) of the variance in voter preference for Romney and correctly classified $92.5 \%$ of the cases. As shown in table one, three of the predictor variables made a unique statistical contribution to the model (Direction of the Country, Republican Party affiliation, and the Enabling and Encouraging LPI leadership ratings of Romney.) The strongest predictor was party affiliation with an odds ratio of 43.45 , indicating that Republicans were over 43 times more likely to vote for Romney than another candidate. 
Table 1. Logistic Regression Predicting Voter Preference for Romney

\begin{tabular}{lrrrr}
\multicolumn{1}{c}{ Predictor } & \multicolumn{1}{c}{ B } & \multicolumn{1}{c}{ SE B } & \multicolumn{1}{c}{$p$ value } & \multicolumn{1}{c}{$e^{B}$} \\
\hline Sex & .075 & .375 & .841 & 1.078 \\
Republican & 3.772 & .360 & .000 & 43.455 \\
Pol. Efficacy & .065 & .043 & .130 & 1.067 \\
Dir. Of Country & -5.025 & 1.218 & .000 & .007 \\
(LPI) & & & & \\
Challenge & .061 & .076 & .425 & 1.063 \\
Enable & .227 & .087 & .009 & 1.255 \\
Encourage & -.209 & .083 & .012 & .812 \\
Inspire & .075 & .071 & .291 & 1.078 \\
Model & .078 & .072 & .280 & 1.081 \\
Constant & -8.402 & 1.469 & .000 & .000 \\
\hline
\end{tabular}

Table 2 presents the results predicting intent to vote regressed on sex, Republican Party affiliation, political efficacy, perceptions of direction of the country, and LPI leadership dimension ratings for Mitt Romney. The full model with all predictors was statistically significant, $X^{2}(9, N=548)=42.8, p<.001$, indicating that the model predicted intent to vote. The full model explained between 9\% (Cox and Snell R squared) and $20.5 \%$ (Nagelkerke R squared) of the variance in intent to vote and correctly classified $92 \%$ of the cases. As shown in table 2, only two of the predictor variables, political efficacy, and sex made a unique statistical contribution to the model, with an odds ratio of 1.19 and .40 , respectively.

Table 2. Logistic Regression Predicting Intent to Vote with Republicans and Romney Leadership Ratings

\begin{tabular}{lrrrr}
\hline \multicolumn{1}{r}{ Predictor } & \multicolumn{1}{c}{ B } & \multicolumn{1}{c}{ SE B } & \multicolumn{1}{c}{ Sig. } & \multicolumn{1}{c}{$e^{B}$} \\
\hline Sex & -.902 & .359 & .012 & .406 \\
Republican & .025 & .429 & .953 & 1.026 \\
Pol. Efficacy & .175 & .037 & .000 & 1.191 \\
Dir. Of Country & .880 & .529 & .096 & 2.412 \\
(LPI) & & & & \\
Challenge & -.134 & .073 & .065 & .875 \\
Enable & -.018 & .082 & .830 & .982 \\
Encourage & .057 & .074 & .446 & 1.058 \\
Inspire & .129 & .071 & .072 & 1.137 \\
Model & .073 & .069 & .294 & 1.075 \\
Constant & -3.726 & 1.188 & .002 & .024 \\
\hline
\end{tabular}


Table 3 presents the analyses results predicting voting preference for Barak Obama regressed on gender, Democratic Party affiliation, political ideology, political efficacy, and LPI leadership ratings total for Barak Obama. The full model with all predictors was also statistically significant, $X^{2}(9, N=548)=423.64, p<.001$. This full model explained between 54\% (Cox and Snell R squared) and 72\% (Nagelkerke R squared) of the variance in voter preference for Obama and correctly classified $87.8 \%$ of the cases. As indicated in table three, four of the predictor variables made a unique statistical contribution (sex, Democratic Party affiliation, perceptions of the direction of the country, the modelling dimension of leadership ratings of Obama.) Similar to the model for Romney, the strongest predictor again was party affiliation with an odds ratio of 26.82. The odds ratio for Obama's "modelling" leadership ratings was 1.3.

Table 3. Logistic Regression Predicting Voter Preference for Obama

\begin{tabular}{l|r|r|r|r}
\hline \multicolumn{1}{c|}{ Predictor } & \multicolumn{1}{c|}{ B } & SE B & p value & \multicolumn{1}{c}{$e^{B}$} \\
\hline Sex & .668 & .308 & .030 & 1.951 \\
Democrat & 3.289 & .364 & .000 & 26.823 \\
Pol. Efficacy & -.028 & .032 & .388 & .973 \\
Dir. of Country & 1.589 & .391 & .000 & 4.897 \\
(LPI) & & & & \\
Challenge & -.060 & .059 & .307 & .941 \\
Enable & .064 & .061 & .288 & 1.066 \\
Encourage & .010 & .059 & .864 & 1.010 \\
Inspire & -.032 & .061 & .601 & .968 \\
Model & .245 & .065 & .000 & 1.278 \\
Constant & -5.730 & 1.084 & 1 & .000 \\
\hline
\end{tabular}

Table 4 presents the results predicting intent to vote regressed on gender, Democratic Party affiliation, perception of direction of the country, political efficacy, and the individual dimensions of LPI leadership ratings for Barak Obama. The full model with all predictors was statistically significant, $X^{2}(9, N=548)=60.66, p<.001$, indicating that this model also predicted intent to vote. The full model explained between $10.5 \%$ (Cox and Snell R squared) and $24.5 \%$ (Nagelkerke R squared) of the variance in intent to vote and correctly classified $91.6 \%$ of the cases. Three of the predictors, Democratic Party affiliation, Political Efficacy, and the Encouraging dimension of the LPI make a statistically significant contribution, with an odds ratio of $7.44,1.2$, and 1.16 respectively. 
Table 4.

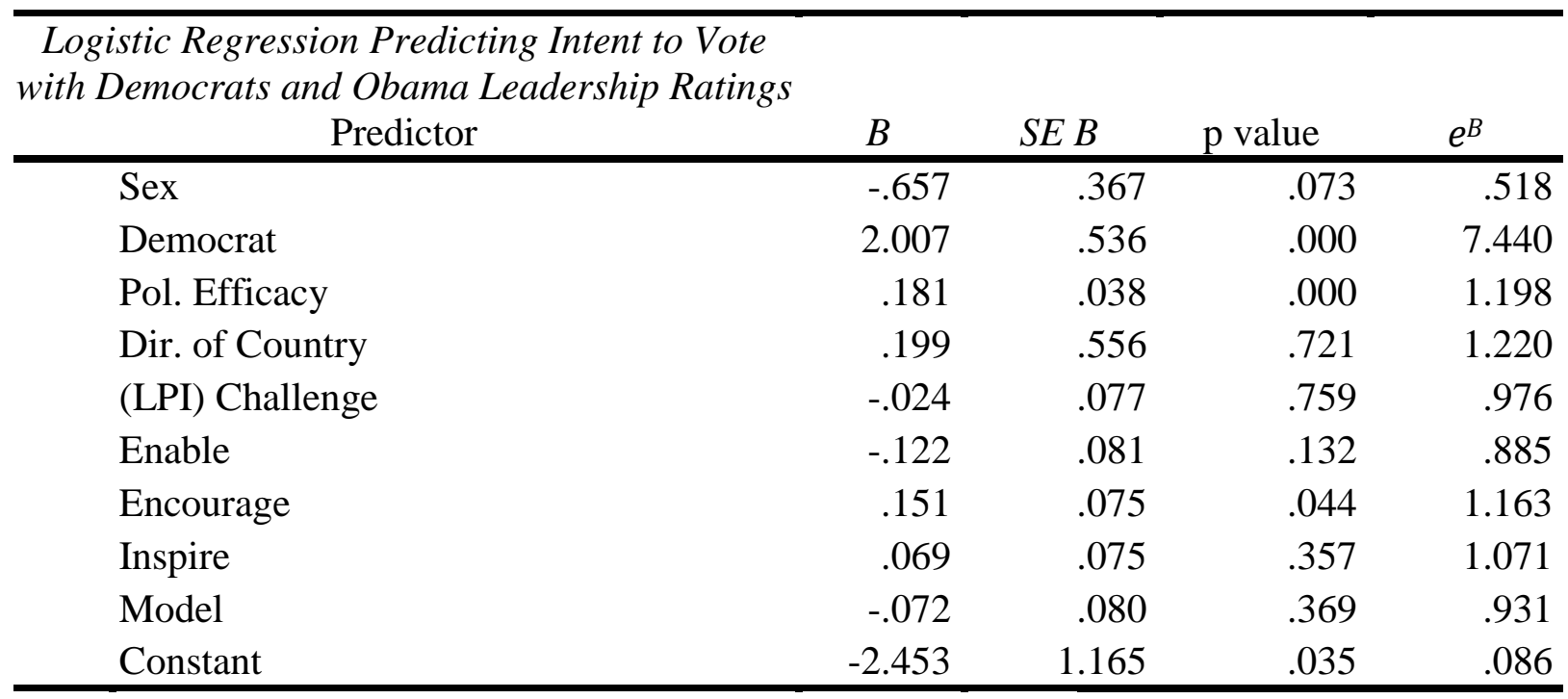

Analysis II. In order to compare Obama's LPI ratings (sub-dimensions and total scores) between 2008 and 2012, we conducted a multivariate analysis employing Hotelling's $t$ and follow-up univariate comparisons for any significant differences; a Bonferroni adjustment (.0083) was calculated to control for family-wise error rate. As hypothesized, the overall model was significant Hotelling's $t=.126, F(9,95.066)=3.9, p$ $<.0001$, partial eta squared $=.112$. Follow-up univariate tests revealed that Obama's ratings in 2008 along all LPI dimensions were significantly higher than in 2012:

Challenge: $F(1,1153)=62.12, p<.0001$, partial eta squared $=.057$; Enable: $F(1,1153)$ $=36.56, p<.0001$, partial eta squared $=.03$; Encourage: $F(1,1153)=7.42, p<.0069$, partial eta squared $=.006$; Inspire: $F(1,1153)=13.82, p<.0001$, partial eta squared $=$ .012 ; Model: $F(1,1153)=8.32, p<.0039$, partial eta squared $=.007$; ; Total LPI: $F(1$, $1153)=25.43, p<.0001$, partial eta squared $=.022$. Table 5 displays relevant descriptive statistics of these comparisons. 
Table 5. Means and Standard Deviations of Obama LPI comparisons between 2008 and 2012.

Comparisons of Obama's LPI Rating Changes (2008 \& 2012)

\begin{tabular}{lcccrr}
\hline LPI & Election Year & & & & \\
Dimension & & $\mathrm{N}$ & \multicolumn{1}{c}{ Mean } & \multicolumn{1}{l}{ Std. Deviation } & Std. Error Mean \\
\hline Challenge & 2008 & 607 & 22.0675 & 5.30431 & .21530 \\
& 2012 & 548 & 19.5985 & 5.32966 & .22767 \\
\hline Enable & 2008 & 607 & 21.8353 & 5.63018 & .22852 \\
& 2012 & 548 & 19.8321 & 5.61184 & .23973 \\
\hline Encourage & 2008 & 607 & 22.4399 & 4.82902 & .19600 \\
& 2012 & 548 & 21.6934 & 4.44024 & .18968 \\
\hline Inspire & 2008 & 607 & 23.8748 & 5.36467 & .21775 \\
& 2012 & 548 & 22.7281 & 5.08439 & .21719 \\
\hline Model & 2008 & 607 & 21.8995 & 5.94902 & .24146 \\
& 2012 & 548 & 20.9142 & 5.62168 & .24015 \\
\hline LPI Total & 2008 & 607 & 112.1170 & 25.40181 & 1.03103 \\
& 2012 & 548 & 104.7664 & 23.97775 & 1.02428 \\
\hline
\end{tabular}

\section{Discussion and Implications for Leadership Educators}

The original study (Popa, Hazel, Whatley, Andenoro, Crandall, 2011) investigated the relationship between young voters' leadership assessment of presidential candidates during the 2008 presidential election and found that leadership assessments have a significant predictive power of candidate preference after controlling for the impact of party identification and self-perceived political efficacy. Political efficacy significantly predicted respondents' intent to vote in the 2008 election after controlling for these same variables. Party affiliation showed to be the most significant difference across political ideology, leadership ratings, political efficacy, and likelihood of voting variables. In light of these findings, along with support from Pillai and Williams (1998), Crespi (1998), and Hogg (2001), the current study predicted that (H1) young voter perceptions of presidential candidates' leadership practices predict intent to vote for a particular candidate after controlling for party affiliation, and (H2) party affiliation predicts differences in perceived leadership practices of the two candidates. Findings suggest three overarching implications for leadership educators: (1) the presence of social belonging to a political party shapes a partisan political identity in young adulthood, (2) the role of congruence between personal values and perceptions of leadership capacity shapes voting rationale, and (3) the social charismatic bond between leader and observer is internalized by the lifespan and social development of the young voter.

Social Belonging. The study of the 2012 presidential election replicated 2008 findings showing that leadership perceptions are consistently held down party lines. Most poignantly, it was predicted that party affiliation continues to carry the most influence in forming impressions of presidential leadership capacity. The point that party affiliation is significant in leadership perceptions of presidential candidates underscores the presence 
of social identity theory and that sense of pride, esteem and efficacy is found in belonging and self-identifying with a group (Tajfel \& Turner, 1979) that may shape personal values and perceptions of presidential candidates.

Additionally, party affiliation may offer young voters an opportunity to maintain value congruence between leadership perceptions and how they define or articulate personal values. Williams, Pillai, Deptula \& Lowe (2012) found that value congruence played a role between cynicism and attributed charisma for Obama (but not for McCain), and between cynicism and perceptions of authentic leadership for McCain (but not for Obama). The authors showed how the relationship between these variables is amplified further in the context of perceived crisis and cynicism. These consistent trends provide leadership educators context for raising student awareness about the role and power of group identity and affiliation when studying leadership. Students may learn that followership is influenced by creating a leadership connection to specific personal or group values. Connection between leader and follower may represent distinctive leadership practices, messaging and communication, and modeling the way.

Value-Congruence. The prediction that partisan leadership ratings continue to also predict voting preferences in the 2012 presidential election was confirmed. Democrats rated Obama significantly higher across all leadership dimensions whereas republicans rated Romney significantly more favorably than did democrats or other voters. The prediction was drawn based on previous research (Pillai \& Williams, 1998; Popa et al. 2011) but reconfirmed in spite of contextual factors that show to be important determinants in evaluating presidential greatness (Kenney \& Rice, 1988; William, Pillai, Deputla \& Lowe, 2010). The evidence that young voters evaluate presidential leadership practices exclusively based on political ideology or party affiliation appears to be a credible and evidence supported plausibility.

In light of replicated findings, a predictive model indicates that voters differentiated on the leadership factors that are important to them. Those who identify as republican and democratic voters were highly interested in the direction of the country. The context of the 2012 election was shaped by a recession, health care reform, domestic and foreign policy, and much more that shaped impression of leadership practices. Young republican voters were most drawn to Mitt Romney based on their impressions of his leadership capacity to strengthen others by increasing self-determination and developing independence and competence. They saw Romney as someone with the capacity to build trust and facilitate relationships, while also showing appreciation for individual differences. On the other hand, Democratic voters also saw their own respective party leader and incumbent president as one who also encourages the heart by showing appreciation for individual differences and creating a spirit of community.

Unlike the 2008 presidential election that was primed with opportunities for candidates to showcase behaviors of heroic leadership images in the minds of voters, the context of the 2012 election was informed by either perceived progress or regression. Voters of both parties were now informed by the track record of an incumbent democratic president and a second presidential run for the republican candidate. In light of the 
incumbency context and the evidence that voters vote for candidates that bring them comfort or fit most pressing needs (Winter, 1987), those who believed the country is heading in the right direction voted Obama and those who believed the country is off on the wrong track voted Romney. Although these trends may not appear earth shattering, what is important to note is that young voters unsure about the direction of the country, potential swing voters still voted for Obama. The trend that potential swing voters still voted for Obama reconfirms the power and significance of the outreach invested by the Obama campaign to connect with the nominal young voter through various platforms of communication and further personalize a message for young voters. Merolla, Ramon, and Zechmeister (2007) studied the 2004 election and found that voters were not only more willing to overlook policy mistakes in a previous terms but perhaps attribute even more hopeful and heroic candidate leadership behaviors to match the current needs of the nation. Although the 2012 election was still under a noticeable shadow of a global financial recession, partisan and swing voters supported the candidate that best articulated a personal leadership narrative with the needs of young voters. Leadership educators may utilize these consistent findings to explain the significance of aligning leadership practices with messaging that represents values of followers. In turn, students of leadership may develop strategic knowledge to mine for the values of followers and then apply procedural skills to lead with focus and efficacy based on the needs of the constituency.

Social Charismatic Bond. Matching perceived presidential leadership practices with needs of young voters is potentially important given that this voting base is developmentally situated in a life stage of identity formation. Erikson (1950) characterized the developmental stage of current college millennials as one of transition between adolescence and adulthood, balancing decisions related to identity formation and solving issues related to direction in life and vocation. Young voters represent a generational cohort brought up in a more racially and ethnically diverse context with potentially single or blended families. Millennials have more open views about diversity, gender, sexism, class, and social justice (Broido, 2004). Additionally, millennials are more demanding of secure environments, respectful of norms and institutions, conventionally minded, and potentially conformist in thinking (Howe \& Strauss, 2003) and less likely to challenge authority (Wilson, 2004).

The generational cohort descriptors by Howe and Strauss (2003) convey what is of most significance to young voters during the college years. Although female and male millennial voters represented a similar generational cohort, they reported different values important in life during the college years. Female voters indicated that finding purpose and meaning in life is of most significance during college years, whereas male students reported academic excellence to be of most significance. Coincidentally more female students were congruent with the value base of the Democratic Party and voted for a candidate that spoke to existential principles. These trends support Shamir's (1995) investigation of charismatic leadership and how the perceived social distance between leaders and followers will impact the leadership capacity attributed to a leader. More female students voted for Obama than male students because of a social charismatic bond or match between their values and the perceived leadership practices of the incumbent 
president. On the other hand, male students indicated that academic excellence is of most significance during college years. Fewer male students voted for the incumbent possibly because their charismatic bond was challenged by unmatched realities of a bleak job market following graduation. This does not mean that male students were exclusively concerned about the economy. The economy was of utmost concern for male and female young voter respondents across all undergraduate classes, even when controlling for timing of acquired political views, religion, or other demographic variables. The importance of context on the impressions of young voters was clearly observed by the significant shift in perceptions about presidential leadership practices of the incumbent president.

Different impressions of presidential candidates found in the same generational cohort are noteworthy because it shows personalized connection with a candidate. These trends may be reflective of a charismatic bond created between candidates and voters. Madsen and Snow (1991) described charismatic bond as a successful match between crisis and a certain leadership approach whereby voters attribute charisma or a set of realistic or unrealistic competencies onto a leader they believe is competent of restoring order or a way of life they desired apart from crisis. These implications highlight the importance of personalizing the message of a candidate to the readiness, sophistication, and context of voters, especially as evidence continues to highlight that perceptions of leadership and the processing of issue-relevant information predicts voting behavior (Maurer et al., 1993; Pillai \& Williams, 1998; Popa, et al., 2011).

\section{Recommendations for Further Research}

The current study added validation to the role of context, the presence of perceived leadership practice, and strength of party affiliation when voting for a U.S. President. The prediction that impressions of leadership practices predict intent to vote for a particular candidate after accounting for party affiliation were confirmed. Additionally, party affiliation also predicts differences in perceived leadership practice of the two candidates. As with previous studies (Maurer, et al., 1993; Pillai \& Williams, 1998; Popa et al., 2011), external validity and generalizability to a larger audience is limited by the representation of a relatively homogenous sample and the context it represents. A more heterogeneous national sample that is more widely reflective of the electorate would contribute to wider representation and implications for young voters.

Findings and narrow scope of interpretation also conveys a need to integrate methodological traditions that investigate the intricacies of complex variables found in social identity theory (Tajfel \& Turner, 1979), the scope of moral imagination (Werhane, 1999) in matching personal values with values of various candidates, and the spectrum of resolving cognitive dissonance (Festinger, 1957) in making voting decisions. Perhaps most importantly is to explore the sophistication of thinking and decision making of respondents. Qualitative approaches may open opportunities to investigate critical thinking and reasoning and the process of reflection and cognitive deliberation found in late adolescence and early adulthood years of identity formation. Designing studies to anticipate greater intellectual complexity of young voters may reveal nuances about a 
generational cohort that continues to shape its intelligent participation in the political process.

\section{Conclusion}

The current study was an extension of the Pillai and Williams (1998) study that first investigated the role of transformational leadership on voting behavior and it was also additional confirmation on the Popa et al., (2011) study that further underlined party affiliation to be a strong determinant in voter choices and a bias in assessment or perception of a leader's abilities and attributes. It is interesting to note that even among biased or partisan assessment of presidential leadership, there was differentiation among female and male young voters based on contextual factors, value congruency, and the perceived charismatic bond with the candidate. Future research needs to mobilize on the cognitive structures that inform and shape impressions and the narratives that young voters construct about presidential candidates. Survey research will continue to add to broader and more heterogeneous representations while qualitative traditions will expose the intricacies of how young voting decisions are constructed and to understanding scripts that contribute to a more sophisticated understanding of intelligent political participation. The overarching contributions of this study was to expand the knowledge base of pioneering studies in the field of political leadership and continue to expose new possibilities of understanding the complexities of political identity formation in young voters.

\section{References}

Abu-Tineh, A., Khasawneh, S., Omary, A. (2009). Kouzes and Posner's Transformational Leadership Model in Practice: The Case of Jordanian Schools. Journal of Leadership Education, 7(3), 265-283.

Antonakis, J., Avolio, B., \& Sivasubramaniam, N. (2003). Context and leadership: An examination of the nine-factor full-range leadership theory using the Multifactor Leadership Questionnaire. Leadership Quarterly, 14(3) 261-295.

Barnett, K., McCormick, J., \& Conners, R. (2001). Transformational leadership in Schools-panacea, placebo, or problem? Journal of Educational Administration, 39(1), 24-46.

Bass, B. M. (1985). Leadership and performance beyond expectations. New York, NY: Free Press.

Bass, B. M. (1996). New paradigm of leadership: an inquiry into transformational leadership. Alexandria, VA: U.S. Army Research Institute for the Behavioral and Social Sciences

Bass B. M., Avolio B. J. (1994a). Improving organizational effectiveness through transformational leadership. Thousand Oaks, CA: Sage Publications. 
Bass, B. M.; Avolio, B. J., (1994b). Transformational leadership and organizational culture. International Journal of Public Administration, 17(3-4), 541-552.

Bennett, W. L. (1995). The clueless public: Bill Clinton meets the new American voter in campaign '92. In S. A. Renshon (Ed.), The Clinton presidency: Campaigning, governing and the psychology of leadership (pp. 91-112). Boulder, CO: Westview Press.

Bueker, C. S., Harris, L. and Byrnes, H., 2009-08-08 "Identifying Predictors of Voter Participation and Candidate Choice among College Students in the 2008 Presidential Election" Paper presented at the annual meeting of the American Sociological Association Annual Meeting, Hilton San Francisco, San Francisco, CA Online <PDF>. 2014-11-29 from http://citation.allacademic.com/meta/p307868_index.html

Crespi, I. (1998). Pre-election polling: Sources of accuracy and error. New York, NY: Sage.

Cronin, T. \& Genovese, M. (2012). The Paradoxes of the American Presidency. New York, NY: Oxford University Press

Day, D. (2000). Leadership development: A review in context. The Leadership Quarterly, 11(4), 581-613.

D'Elia, J. \& Norpoth, H. (2014). Winning with a bad economy. Presidential Studies Quarterly, 44(3) 467-483.

Emrich, G. G., Holly, H. H., Feldman, J. M., \& Garland, H. (2001). Images in words: Presidential rhetoric, charisma, and greatness. Administrative Science Quarterly, 46, 527-557.

Engbers, T. \& Fucilla, L. (2012). Transforming leadership and the Obama presidency. Social Science Quarterly, 93(5), 1127-1145.

Erikson, E. H. (1950). Childhood and society. New York, NY: Norton.

Festinger, L. (1957). A Theory of cognitive dissonance. Stanford, CA: Stanford University Press.

Foti, R. J., Fraser, S. L., \& Lord, R. G. (1982). Effects of leadership labels and prototypes on perceptions of political leaders. Journal of Applied Psychology, 3, 326-333.

Gibson, J. L., Ivancevich, J. M., Donnelly Jr., J. H., \& Konopaske, R. (2012). Organizations, behavior, structure, processes. (14 ${ }^{\text {th }}$ ed.). New York: McGraw-Hill 
Goethals, G. R. (2005). Presidential leadership. Annual Review of Psychology, 56, 545570.

Green, D. \& Roberts, G. (2012). Transformational leadership in a postmodern world: The presidential election of Barack Obama. Academy of Strategic Management, 11(1), 9-25.

Green, D. (2007). Leading in a postmodern workforce. Academy of Strategic Management Journal, 6, 15-26.

Hater, J. J., \& Bass, B. M. (1988). Superior's evaluations and subordinate's perceptions of transformational and transactional leadership. Journal of Applied Psychology, 73(4), 695-702.

Hogg, M. A. (2001). A social identity theory of leadership. Personal Social Psychology Review, 5, 184-200.

Hunt, J. G., Boal, K. B., \& Dodge, G. E. (1999). The effect of visionary and crisisresponsive charisma on followers: An experimental examination of two kinds of charismatic leadership. Leadership

Quarterly, 10(3), 423-448.

Hohman, Z., Hogg, M., \& Bligh, M. (2010). Identity and intergroup leadership. Asymmetrical political and national identification in response to uncertainty. Self Identity, 9, 113-128.

Holian, D., \& Prysby, C. (2014). Candidate Character Traits in the 2012

Presidential Election. Presidential Studies Quarterly, 44(3) 484-505.

Howe, N., \& Strauss, W. (2003). Millennials go to college. Great Falls, WA: American Association of Registrars and Admissions Officers and Life Course Associates.

Kark, R. \& Shamir, B. (2002). The influence of transformational leadership on follower relational versus collective self-concept. Academy of Management Proceedings, D1-D6.

Kenney P. J., \& Rice, T. W. (1988). The contextual determinants of presidential greatness. Presidential Studies Quarterly, 18, 161-169.

Kouzes, J., \& Posner, B. (2007). The Leadership Challenge, John Wiley \& Sons, Inc., San Francisco, CA.

Madsen, D., \& Snow, P.G. (1991). The charismatic bond: Political behavior in times of crisis. Cambridge, MA: Harvard University Press. 
Maurer, T. J., Maher, K. K., Ashe, D. K., Mitchell, D.R.D., Hein, M. B., \& Hein, J. V. (1993). Leadership perceptions in relation to presidential vote. Journal of Applied Social Psychology, 23(12), 959-979

Merolla, J. L., Ramos, J. M., \& Zechmeister, E. J. (2007). Crisis, charisma, and consequences: Evidence from the 2004 U.S. presidential election. Journal of Politics, 69(1), 30-42.

Niemi, R. G., Craig, S. C., \& Mattei, F.. (1991). Measuring internal political efficacy in the 1988 national election study. The American Political Science Review, 85(4), 1407-1413. http://doi.org/10.2307/1963953

O’Hare, R., Walter, M., \& Christopher, A. (2009). Need for cognition and conscientiousness as predictors of political interest and voting strategy. Journal of Applied Psychology, 39(6), 1397-1416.

Pew Research Center for the People and the Press (2012). Young voters supported Obama less, but may have mattered more. November 26, 2012. http://www.people-press.org/2012/11/26/young-voters-supported-obama-less-butmay-have-mattered-more/

Pillai, R., \& Williams, E. (1998). Does leadership matter in the political arena? Voters perceptions of candidates' transformational and charismatic leadership and the 1996 U.S. presidential vote. Leadership Quarterly, 9(3), 397.

Pillai, R., \& Meindl, J. R. (1998). Context and charisma: A "meso" level examination of the relationship of organic structure, collectivism, and crisis to charismatic leadership. Journal of Management, 24(5), 643-671.

Popa, A.B., Hazel, M., Whatley, L., Andenoro, A., \& Crandall, H. (2011). What is the role of perceived leadership capacity in presidential politics? Young voters' perceptions of candidates' leadership practices and the 2008 U.S. presidential race. Journal of Leadership Studies, 5(3), 25-39.

Shamir, B. M. (1995). Social distance and charisma: Theoretical notes and an exploratory study. Leadership Quarterly, 6, 19-47.

Shamir, B.M., \& Howell, J. M. (1999). Organizational and contextual influences on the emergence and effectiveness of charismatic leadership. Leadership Quarterly, 10(2), 257-283.

Simonton, D. K. (2001). Predicting presidential performance in the United States: Equation replication on recent survey results. Journal of Social Psychology, 141(3), 293-307. 
Tajfel, H., \& Turner, J. C. (1979). An integrative theory of intergroup conflict. The social psychology of intergroup relations, 33, 47.

Werhane, P. (1999). Moral imagination and management decision making. New York: Oxford Press.

William, E., Pillai, R., Deptula, B., \& Lowe, K. (2012). The effects of crisis, cynicism about change, and value congruence on perceptions of authentic leadership attributed charisma in 2008 presidential election. The Leadership Quarterly, 23(3), 324-341

William, E., Pillai, R., Deptula, B., \& Lowe, K. (2009). Crisis, charisma, values, and voting behavior in the 2004 presidential election. The Leadership Quarterly, 20(2), 70-86

Winter, D.G. (1987). Leaders appeal, leader performance, and the motive profiles of leaders and followers: A study of American presidents and elections. Journal of Personality and Social Psychology, 52(1), 196-202.

Yukl, G. (1994). Leadership in Organizations ( $3^{\text {rd }}$.ed.). Englewood Cilffs, NJ: Prentice-Hall. 